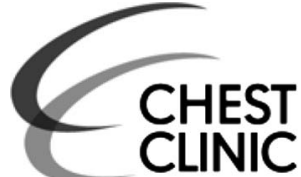

${ }^{1}$ Department of

Histopathology, Norfolk and Norwich University Hospital,

Norwich, UK

${ }^{2}$ Department of

Histopathology, Norfolk and Norwich NHS Trust, Norwich, UK

${ }^{3}$ Department of Respiratory Medicine, James Paget NHS Trust, Great Yarmouth, UK

\section{Correspondence to}

Dr Shroque Zaher, Department of Histopathology, Norfolk and Norwich University Hospital, Colney Lane, Norwich NR4 7UY, UK; drruki@hotmail.com

Received 21 April 2016 Revised 19 June 2016 Accepted 6 July 2016 Published Online First 3 August 2016

\title{
Sevelamer crystals in the bronchus: a case report
}

\author{
Shroque Zaher, ${ }^{1}$ Ahsan $\mathrm{Ali}_{1}{ }^{2}$ Paul Babu ${ }^{3}$
}

\section{HISTORY}

An 80-year-old woman was admitted with a history of cough and gradually worsening shortness of breath of 3 months duration. Respiratory system examination revealed tracheal shift to the left, together with impaired percussion, diminished breath sounds and crackles at the left base. Her medical history included chronic renal failure for which she received haemodialysis three times a week. Her current medications included Sevelamer tablets $800 \mathrm{mg}$ three times a day. The patient was on this particular medication for a period of 10 months prior to admission. There was no history of any previous respiratory disease. Chest X-ray showed a complete collapse of the left lung

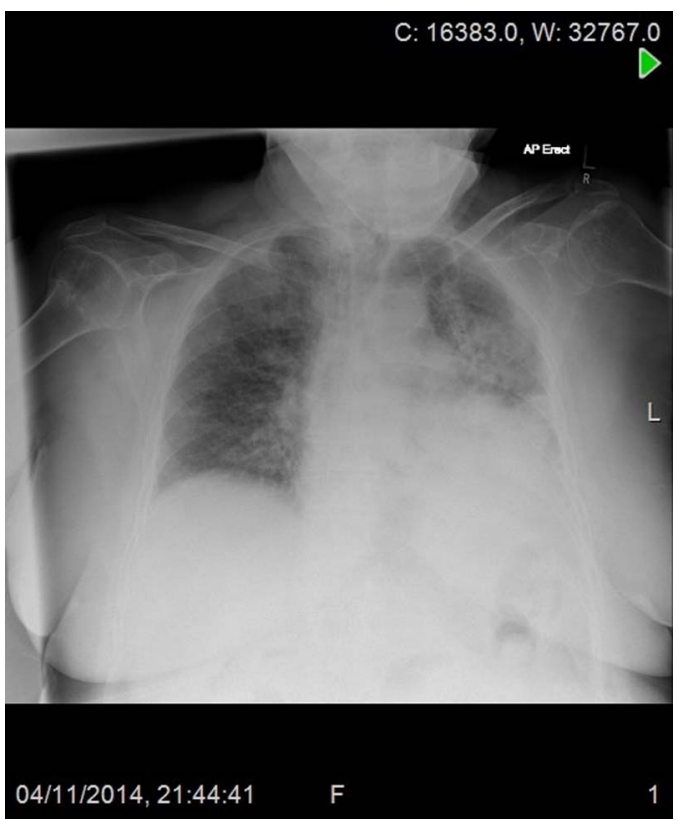

Figure 1 Chest X-ray: Complete collapse of left lung.

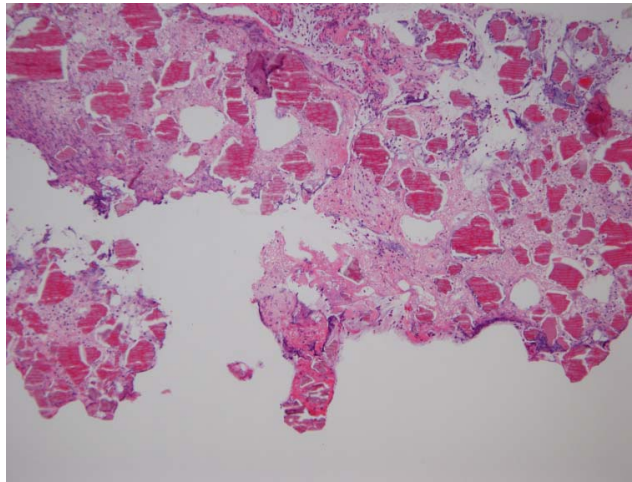

Figure 2 Low power view of crystals. (figure 1) which was confirmed on CT thorax. There was no distinct endobronchial or hilar pathology. A bronchoscopy showed significant inflammation of the distal left main bronchus with mucopurulent secretions in the left lower lobe. The mucosa was abnormal, appearing diffusely thickened. Bronchial washings and biopsies were taken.

Cytology showed several fragments of laminated crystalline material. The biopsies comprised an acute inflammatory slough with tiny fragments of ulcerated mucosa. Within the inflammatory slough, there were numerous crystalline forms composed of a pink material with regular internal demarcations resembling fish scales (figures 2 and 3 ).

The morphological appearance of the crystals appeared identical to crystals seen in the gastrointestinal tract in patients treated with the drug Sevelamer. ${ }^{1}$ A diagnosis of chronic aspiration of Sevelamer resulting in bronchial crystal deposition was made.

\section{DISCUSSION}

The accumulation of drugs with resulting mucosal injury in the respiratory tract is unusual. ${ }^{2}$ Sevelamer is used to treat hyperphosphataemia in dialysis patients. It is a non-absorbable resin drug, used for ion exchange in the gastrointestinal (GI) tract. $^{3}$ It is one of many drugs known to cause mucosal injury in the GI tract.

When deposited in tissues, its crystals have a unique histological appearance. As shown in figures 2 and 3, the characteristic crystals have broad, curved internal demarcations or 'fish-scales' with a two-toned colour of bright pink linear accentuations with a rusty yellow background. They can be highlighted magenta with an acid-fast bacilli stain. ${ }^{4}$

\section{CONCLUSION}

With increasing use of resin drugs, especially Sevelamer, it is important to recognise the

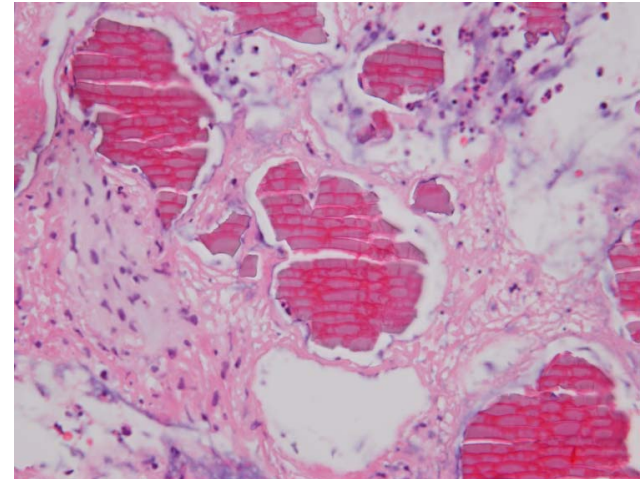

Figure 3 High power view of crystals. 
histological appearances of these drugs and be aware that the drug may be deposited at sites other than the GI tract.

Contributors SZ wrote the abstract, microscopy, discussion and conclusion sections of the case report. AA diagnosed the case, supplied the photos and was responsible for overall review of the report. PB wrote the clinical history section of the report.

Competing interests None declared.

Patient consent Obtained.

Provenance and peer review Not commissioned; externally peer reviewed.

\section{REFERENCES}

1 Swanson BJ, Limketkai BN, Liu TC, et al. Sevelamer crystals in the gastrointestinal tract (GIT): a new entity associated with mucosal injury. Am I Surg Pathol 2013;37:1686-93.

2 Voltaggio L, Lam-Himlin D, Limketkai BN, et al. Message in a bottle: decoding medication injury patterns in the gastrointestinal tract. J Clin Pathol 2014;67:903-12.

3 http:/WWW.Druglib.com/druginfo/renvela/description_pharmacology/

4 Arnold MA, Swanson BJ, Crowder CD, et al. Colesevelam and colestipol: novel medication resins in the gastrointestinal tract. Am Surg Pathol 2014;38: 1530-7. 